\title{
Colostrum Avoidance Practices and Its Associated Factors Among Mothers of Children Aged Less Than 12 Months in Jinka Town, South Ethiopia, 2019
}

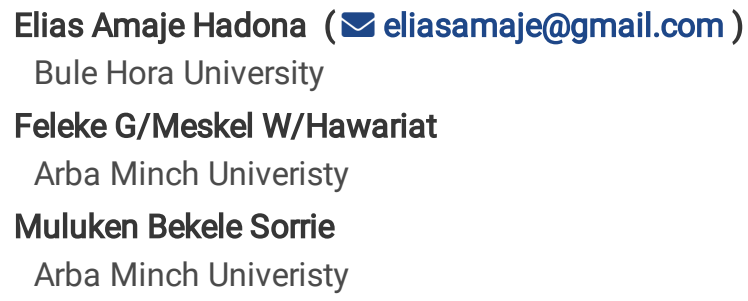

Research

Keywords: Colostrum avoidance, Associated factors, Jinka town, Ethiopia

Posted Date: July 28th, 2020

DOI: https://doi.org/10.21203/rs.3.rs-48987/v1

License: (1) This work is licensed under a Creative Commons Attribution 4.0 International License. Read Full License 


\section{Abstract}

Introduction: Colostrum avoidance is the common nutritional malpractices in developing countries including Ethiopia. Discarding colostrum is the main causes of respiratory disease and diarrheal disease during childhood and contributes to over a million avoidable infant deaths each year and remains a public health problem in developing countries. Despite the fact that it has a negative effect on child health, little is known about the extent of the problem and its contributing factors in South Ethiopia particularly in study area. The aim of the study was to determine the prevalence of colostrum avoidance practices and associated factors among Mothers of children aged less than 12 months in Jinka Town, South Ethiopia.

Methods: A community based cross-sectional study was conducted at Jinka Town from March 1 to 30, 2019. A total of 420 mothers having children less than 12 months of age were selected by systematic sampling technique. The data were collected by using pretested interviewer administered and semi-structured questionnaires. The data was entered using EPIDATA 3.1 and exported to SPSS version 23 for analysis. Descriptive statistics, Binary and multivariable logistic regression analysis were done. An adjusted odds ratio with $95 \% \mathrm{Cl}$ at a $\mathrm{p}$-value $<0.05$ was estimated to identify statistically significant variables with colostrum avoidance practices.

Results: The prevalence of colostrum avoidance practice was $9.8 \%$ [95\% Cl: (6.9-12.5)]. Delayed initiation of breast feeding [AOR= 9.08(95\% Cl 4.16-19.83)], Lack of breast feeding counselling [AOR=2.33(95\% $\mathrm{Cl} 1.11-4.87)]$, Home delivery of index child [AOR=2.48 (95\% $\mathrm{Cl} 1.16-5.27)]$ and Poor knowledge on breast feeding [AOR=4.55(95\% $\mathrm{Cl} 1.95-10.63)]$ were factors associated with colostrum avoidance practices.

Conclusions: Colostrum avoidance practice among mothers of children aged less than 12 months in Jinka town was high. Delayed initiation of Breas feeding, lack of breast feeding counselling, Home delivery and knowledge on breastfeeding feeding practice were factors associated with colostrum avoidance practice. Promoting institutional delivery services and strengthening of breast feeding counselling during antenatal and postnatal care were recommended for the promotion of the nutritional value of colostrum and its health benefits.

\section{Introduction}

Breastfeeding is considered a proven child survival strategy, and the World Health Organization (WHO) recommends that, the newborns to be put on the breast within an hour after birth [1]. It provides immense immunologic, psychological, social-economic, and environmental benefits [2]. It also significantly reduces a child's risk of developing obesity, type 2 diabetes mellitus and related chronic non-communicable diseases[3]. Furthermore, breastfeeding promotes a child's cognitive development [4]. Early initiation of breastfeeding immediately after birth enhances mother-infant bonding [5]. Moreover, it promotes effective suckling, successful establishment, and maintenance of breastfeeding throughout infancy [6]. However, in different countries including Ethiopia, a significant proportion of mothers offer prelacteal feeds to their newborn [7-9].

Colostrum is the first liquid that is produced in the first few hours after delivery. It is thick, sticky and clear to yellowish in color. It contains proteins, vitamin A and maternal antibodies important to the newborn's nutrition until lactation is fully established [10]. Colostrum establishes important bacteria in the baby's gut. It also acts as 'paint', coating the infant's gastrointestinal tract. Therefore, colostrum provides natural immunity (baby's first immunization) against many bacteria and viruses [10,11]. In contrary to these advantages, colostrum is considered heavy, thick, dirty, toxic and harmful to children's health and therefore in some societies, a portion of colostrum is discarded. Colostrum avoidance is a common practice in Ethiopia [12, 13]. It is the low-volume concentrated form of nutrient supply system, which suits for newborns with premature digestive system. It has laxative effect which encourages passage of baby's first stool, meconium. This help to prevent neonatal jaundice by clearing excess amount of bilirubin, which is produced in large quantities at a birth $[14,15]$.

Colostrum feeding is associated with a reduced risk of otitis media, gastroenteritis, and respiratory illness, necrotizing entero-colitis, obesity, and hypertension [16]. In the developing countries where the rate of communicable diseases is high, timely provision of colostrum is reducing diarrheal disease in the neonates [17].

Globally, more than 4000 infants and young children die because they do not get colostrum within the first hour after birth. Most of the infants are given liquids other than their mother's milk in the first few days after birth. The rate of breastfeeding varies in 
communities from almost $70 \%$ to a low of $13 \%$ as this is culturally influenced [18]. Among women in developing countries who do not give colostrum feeds, most of them avoid colostrum feeding based on cultural beliefs that range from no nutritional value for infants to harmful for the infant's health. Some women may specify no reason for avoiding colostrum rather than tradition [19].

Globally, colostrum avoidance is practiced in many countries; In Utarkhand, India $92 \%$ of mother discarded colostrum, In Nepal 16.5\%, In Pakistan 27.9\% and in Burkina Faso 16\% of mothers deprived colostrum to their infants [20-23]. In Ethiopia, colostrum discarding is the common nutritional malpractice. In Afar 35\%, in Debre Tabor 25.6\% in Raya kobo 13.5\%, in Axum 6.3\% and in Motta Town $20.3 \%$ of mother reported that they discarded colostrum [24-27] [28].

Every day, 3000-4000 infants die in the developing world from diarrhea and acute respiratory infections because they were receiving inadequate amounts of breast milk in their feeding and were deprived colostrum [29]. In particular, $45 \%$ of neonatal infectious deaths, $30 \%$ of diarrheal deaths, and $18 \%$ of acute respiratory deaths among children aged less than five years are associated with suboptimal breast feeding $[30,31]$.Malnutrition is an underlying factor in more than $50 \%$ of the major cause of infant mortality and the risk of malnutrition in children during the first 2 years of life is an indication of poor infant feeding practices [32] .A Study carried out in Afambo district, Afar found that children who were colostrum avoided had 2.34 times increased likelihood of being underweight when compared to those children who fed colostrum [33]. Suboptimal breast feeding is also one of the risk factor for childhood stunting [34]. Poor infant feeding practices are chief challenges to the social and economic development of one country [35].

Different factors were noted to affect colostrum avoidance practice; it was mainly related to maternal characteristics. Accordingly, home delivery, failure to attend ANC, lack of post-natal care, late breastfeeding initiation and poor knowledge on optimal breast feeding $[26,27,36]$.

A wide range of harmful new born feeding practices are documented in Ethiopia even after the implementation of infant and young child feeding guideline [37]. In cognizance of the severity as well as the wide spreading practices of inappropriate breastfeeding, the Government of Ethiopia has been devising different strategies including generating of health extension program, and working in collaboration with Non-Governmental Organizations (NGOs) in the areas of IYCF [38, 39]. WHO and UNICEF recommend that children should initiate colostrum within the first hour of birth, However in Ethiopia about $27 \%$ of infant had not started colostrum within one hour of birth $[40,41]$. Despite the fact that colostrum avoidance has a negative effect on child health, little is known about the extent of the problem and its contributing factors in Southern Ethiopia particularly in study area. As there are diverse cultural practices among Ethiopian communities, evidence generated by this study will assist in developing context specific interventions to halt colostrum avoidance practice and to promote optimal IYCF practice. Therefore, the purpose of this study was to assess the prevalence of colostrum avoidance practices and its associated factors among mothers of children aged less than 12 months in Jinka Town, Southern Ethiopia.

The finding of this study may add knowledge about the magnitude and its determinants of colostrum avoidance and to come up with recommendation on possible intervention for colostrum avoidance and association factors in the study area. This study will also help to health care service provider in their counseling/health education session to strength good breast-feeding practices. It helps Town Health office and Zonal Health department by providing relevant information for future planning and interventions of appropriate strategies to promote colostrum feeding. This in turn, may help to reduce the mortality and morbidity rate of infant in Ethiopia. The finding of this study also helps for local NGOs working in the areas of child health to improve optimal breast feeding practices.

\section{Methods And Materials}

\section{Study setting, design and period}

This study was conducted in Jinka Town, South Omo Zone and is situated $755 \mathrm{Km}$ away from Addis Ababa and $525 \mathrm{Km}$ from Hawassa. The Town has an estimated population size of 31226 living in 6 kebeles (the smallest administration unit in Ethiopia). Out of total population 15582 are males and 15644 are females. Out of all female population 6076 are women in the reproductive age group (15-49 year). About 997 of the total population are accounted by children less than one years of age. The Town has 1 hospital, 1 health center and 6 health posts providing health services including maternal and child health care. The town also has 12 private clinic and 13 drug vendors [42]. The study period was from March 1 to 30, 2019. 
A community based cross-sectional study was conducted to determine the prevalence of colostrum avoidance and associated factors among mothers of children aged less than 12 months in Jinka Town, South Omo Zone, Ethiopia.

\section{Source population}

All mothers of children aged less than 12 months in Jinka Town, South Omo Zone.

\section{Study population}

All mothers of children aged less than 12 months in the selected kebeles of Jinka Town during data collection period.

\section{Eligibility criteria}

Inclusion criteria

All mothers/caregivers of children aged less than 12 months and mothers who had lived for at least for 6 months in the study area.

\section{Exclusion criteria}

Those mothers who was seriously ill or unable to give the required information during data collection period.

\section{Sample Size and Sampling Technique}

In this study, the sample size is determined by using single population proportion formula. Considering the prevalence of colostrum avoidance practices of $20.3 \%$ obtained from previous study conducted in Motta Town [28], 95\% certainty and maximum discrepancy of $5 \%$ between the sample size and the underlining population. The following single population formula:

By using design effect of 1.5 and by adding $15 \%$ of non-response rate, total sample size is

$249 * 1.5+15 \%=430$. Thus, the final sample size was $n=430$ mothers.

Systematic sampling technique was employed to select study participants. From total of 6 kebeles of Jinka Town 4 Kebeles was selected by Lottery Method. In order to obtain the sample size from each selected kebeles proportional allocation to sample size was done. First, numbering of all households of selected kebeles with mothers of children aged less than 12 months was conducted, and then systematic sampling technique was applied for selection of study participants. Finally, every $k^{\text {th }}=2$ Mother from each house hold of the selected Kebele's was identified until the required sample size fulfilled and the starting household was selected using a lottery method. At the time of survey, from each household unit one eligible mother who had a child aged less than 12 months was selected. In scenarios where there was more than one potential respondent in a household, simple random sampling was done to select one.

\section{Study variables}

\section{Dependent variable}

Colostrum avoidance practices

Independent variables

Socio-demographic factors: age of the mother, educational status of the mother, educational status of father of index child, marital status, religion, ethnicity, occupation of the mother, household's wealth status, family size and sex of the index child. Maternal health service utilization: ANC visit, BF counseling during ANC visit, place of delivery of index child, mode of delivery of index child and postnatal care. Breast feeding history: delayed initiation of BF and prelacteal feeding practices. Knowledge: mother's knowledge on BF. Maternal health related factors: medical conditions and breast problem

\section{Operational definition and terms}

\section{Colostrum avoidance}

is the failure to feed infants the first, thick and yellowish milk that is produced in the first 3 days after birth. Avoiding colostrum was coded as ' 1 ', while colostrum feeding was coded as '0' for regression analysis [26]. 


\section{Prelacteal feeding}

If an infant within the first three days of life feed something other than breast milk [40].

\section{Delayed initiation of BF}

Initiation of breastfeeding after one hour of birth [40].

\section{Good knowledge of breastfeeding practice}

If a mother answered four questions out of seven on breastfeeding knowledge correctly [28].

\section{Data Collection Tools and Procedure}

A semi-structured interviewer administered questionnaire was used to collect data from mothers of a child. The questionnaire was constructed by adapting from previous literature $[20,25-27,36]$ and contextualized to fit the research objective accordingly. The questionnaire was initially prepared in English and then translated into Amharic version (local language) by different fluent speakers of both languages and then to English to check its consistency. The questionnaire mainly addressed socio-demographic, infant feeding, maternal health services utilization, maternal health related and maternal knowledge on breast feeding practices. The data were collected by four trained diploma nurses who are fluent speaker in the local language and supervised by two BSc public health professionals. Face-to-face interview technique was conducted at the study participants' house. The study participants were properly oriented on the purpose, objectives and usefulness of the study and then questionnaire was provided to respondents after getting written consent from each participant.

\section{Data quality control}

To assure the quality of data, properly designed data collection instruments was provided after appropriate training for data collectors and supervisors. The questionnaire was initially prepared in English and then translated into Amharic version (local language) by different fluent speakers of both languages and then to English to check its consistency. The questionnaire was pretested prior to the actual data collection on $5 \%$ of the sample size in nearby Town, Key Afer in order to check clarity and consistency of data collection instruments. During pre-testing an effort was made to check for consistency in the interpretation of questions and to identify ambiguous items. The collected data was checked for consistency, completeness and relevance on a daily basis during the entire data collection by the supervisors and principal investigator.

\section{Data Processing and Analysis}

The collected data was coded and entered by EPIDATA 3.1 and exported to statistical package for social science (SPSS) version 23.0 for analysis. Then data cleaning, editing recoding and management were carried out. Descriptive statistics; mean, standard deviation and proportion were done. The household wealth index was computed by considering properties, like selected household assets. The wealth index of participants household was computed by Principal component (PCA). Assumptions for factor analysis were checked. Finally, household wealth status was ranked into three categories (poor, middle and rich). Binary logistic regression analysis was employed to examine the statistical association between the colostrum avoidance practices and independent variables. Variables which have $p$ value $<0.25$ during bivariate analysis were entered into multivariable logistic regression to identify statistically significant variables. The model goodness of fit was tested by Hosmer-Lemeshow statistic which is not significant P-value $=0.264$. Multi co linearity test was carried out to see the correlation between all multivariate independent variables using collinearity statistics which is tolerance $>0.1$ and variance inflation factor $<10$. An Adjusted odds ratio (AOR) with $95 \% \mathrm{Cl}$ at a p-value $<0.05$ was estimated to identify statistically significant variables. The data were presented by tables, frequencies and graphs.

\section{Results}

\section{Socio demographic characteristics of mothers and children}

Four hundred twenty Mothers having children less than 12 months of age were interviewed in this study, with a response rate of $98.4 \%$. The mean age of respondents was $26.86(S D \pm 5.06)$ years. A minimum and maximum age of the respondents was 18 and 41 years respectively. Majority of the mothers; 396(94.3\%) were married. About $183(43.6 \%)$ of the respondents had primary level of education. Regarding religion of respondents 259 (61.7\%) were orthodox Christians. Out of the total respondents 181(43.1\%) were 
Amhara in ethnicity. Majority of the respondents; $314(74.8 \%)$ were unemployed in occupation. About $247(58.8 \%)$ of fathers of index child had secondary level of education and above. Concerning family size of the respondents $279(66.4 \%)$ had $\geq 4$ family number. Around half of the children 228(54.3\%) were males (Table 1).

Table 1

Socio-demographic characteristics of Mothers of children aged less than 12 in Jinka town, South Ethiopia,

\begin{tabular}{|c|c|c|c|}
\hline Variables & Category & Frequency(n) & Percentage (\%) \\
\hline \multirow[t]{3}{*}{ Maternal age (year) } & $15-24$ & 141 & 33.5 \\
\hline & $25-34$ & 235 & 56.0 \\
\hline & $\geq 35$ & 44 & 10.5 \\
\hline \multirow[t]{2}{*}{ Marital status } & Married & 396 & 94.3 \\
\hline & Unmarried & 24 & 5.7 \\
\hline \multirow[t]{3}{*}{ Educational status of mother } & Unable to read and write & 63 & 15.0 \\
\hline & Primary education & 183 & 43.6 \\
\hline & Secondary and above & 174 & 41.4 \\
\hline \multirow[t]{4}{*}{ Religion } & Orthodox & 259 & 61.7 \\
\hline & Protestant & 139 & 33.1 \\
\hline & Muslim & 19 & 4.5 \\
\hline & Others & 3 & 0.7 \\
\hline \multirow[t]{6}{*}{ Ethnicity of mother } & Amhara & 181 & 43.1 \\
\hline & Ari & 114 & 27.1 \\
\hline & Gofa & 31 & 7.4 \\
\hline & Wolayta & 42 & 10.0 \\
\hline & Basketo & 42 & 10.0 \\
\hline & Others & 10 & 2.4 \\
\hline \multirow[t]{2}{*}{ Maternal occupation } & Unemployed & 314 & 74.8 \\
\hline & Employed & 106 & 25.2 \\
\hline \multirow[t]{3}{*}{ Educational status of the father of index child } & Unable to read and write & 40 & 9.5 \\
\hline & Primary education & 133 & 31.7 \\
\hline & Secondary and above & 247 & 58.8 \\
\hline \multirow[t]{2}{*}{ Family size } & $\geq 4$ & 280 & 66.7 \\
\hline & $\leq 3$ & 140 & 33.3 \\
\hline \multirow[t]{2}{*}{ Sex of index child } & Male & 228 & 54.3 \\
\hline & Female & 192 & 45.7 \\
\hline \multirow[t]{3}{*}{ Wealth index } & Poor & 140 & 33.3 \\
\hline & Middle & 146 & 34.8 \\
\hline & Rich & 134 & 31.9 \\
\hline
\end{tabular}




\section{The prevalence of colostrum avoidance practices among Mothers}

The prevalence of colostrum avoidance practices in this study was 41 (9.8\%) (95\% Cl: 6.9-12.5). The main reasons for colostrum avoidance were breast milk insufficiency $14(34.1 \%)$ followed by considering colostrum causes abdominal discomfort and diarrhea for the new born 11(26.8\%). Regarding prelacteal feeding; of the total respondents; $53(12.6 \%)$ were practicing prelacteal feeding. The major Reason for prelacteal feeding were; cultural practice 19(35.8\%); by considering breast fed for newborns will be thirsty 10(18.9\%) and to clean infant's bowel/throat $8(15.1 \%)$. Three hundred twenty-four $(77.1 \%)$ of mothers-initiated breast feeding within one hour, while the remaining $96(22.9 \%)$ initiated breast feeding more than one hour (Table 2).

Table 2

Colostrum avoidance practices among mothers of children aged less than 12 months in Jinka town, South Ethiopia, 2018/19 ( $=420)$.

\begin{tabular}{|c|c|c|c|}
\hline Variable & Category & Frequency & Percentage \\
\hline \multirow[t]{2}{*}{ Colostrum avoided (420) } & Yes & 41 & 9.8 \\
\hline & No & 379 & 90.2 \\
\hline \multirow[t]{4}{*}{ Reason for discarding colostrum (41) } & Maternal medical illness & 9 & 22 \\
\hline & Colostrum is not good for child growth & 7 & 17.1 \\
\hline & Breast milk insufficiency & 14 & 34.1 \\
\hline & Causes abdominal discomfort & 11 & 26.8 \\
\hline \multirow[t]{2}{*}{ Pre-lacteal feeding (420) } & Yes & 53 & 12.6 \\
\hline & No & 367 & 87.4 \\
\hline \multirow[t]{8}{*}{ Reason for providing pre-lacteal feeding (53) } & Breast fed for newborn will be thirsty & 10 & 18.9 \\
\hline & Breast problem & 2 & 3.8 \\
\hline & Maternal medical illness & 2 & 3.8 \\
\hline & Inadequate milk secretion & 5 & 9.4 \\
\hline & Infant feeding problem & 4 & 7.5 \\
\hline & Child growth & 3 & 5.7 \\
\hline & Cultural practice & 19 & 35.8 \\
\hline & To clean infant bowel/mouth & 8 & 15.1 \\
\hline \multirow[t]{2}{*}{ Breast feeding initiation (420) } & Within one hour & 324 & 77.1 \\
\hline & Greater than one hour & 96 & 22.9 \\
\hline
\end{tabular}

\section{Maternal health care service utilization and obstetric characteristics}

Three hundred eighty (90.5\%) of mothers have utilized ANC services for their index infants. From those mothers who have utilized ANC services $140(36.8 \%)$ visit four and above. About $268(63.8 \%)$ of respondents had got breast feeding Counseling. From those mothers who were counselled on breast feeding 154(57.5\%) counseled on the benefits of breast feeding. Three hundred twenty-seven (77.9\%) of mothers delivered their child at health facility. Three hundred fifty one (83.6\%) of mothers gave birth through spontaneous vaginal delivery. About $273(65 \%)$ of respondents utilized postnatal care. About $78(28.6 \%)$ of respondents utilized three or more visits. Nearly half $198(47.2 \%)$ of infants were birth order of second and third child. Around half $208(49.5 \%)$ of children were born with birth spacing of greater than 24 months (Table 3). 
Table 3

Maternal health care service utilization among mothers of children aged less than 12 months in Jinka town, South Ethiopia, 2018/19 $(\mathrm{N}=420)$.

\begin{tabular}{|c|c|c|c|}
\hline Variable & Category & Frequency(n) & Percentage (\%) \\
\hline \multirow[t]{2}{*}{ Attending ANC ( $N=420)$} & Yes & 380 & 90.5 \\
\hline & No & 40 & 9.5 \\
\hline \multirow[t]{2}{*}{ Number of Antenatal care visit $(\mathrm{N}=387)$} & $1-3$ visit & 240 & 63.2 \\
\hline & $\geq 4$ visit & 140 & 36.8 \\
\hline \multirow[t]{2}{*}{ Breast feeding Counseling } & Yes & 268 & 63.8 \\
\hline & No & 152 & 36.2 \\
\hline \multirow[t]{5}{*}{ Information from counseling (M) } & Benefit of breastfeeding & 154 & 57.0 \\
\hline & Positioning and attachment & 40 & 14.9 \\
\hline & Exclusive breastfeeding & 88 & 32.8 \\
\hline & Non-breastfeeding problem & 38 & 14.2 \\
\hline & Expressed breastfeeding & 19 & 7.1 \\
\hline \multirow[t]{2}{*}{ Place of Delivery $(\mathrm{N}=420)$} & Health facility & 327 & 77.9 \\
\hline & At Home & 93 & 22.1 \\
\hline \multirow[t]{3}{*}{ Mode of Delivery $(N=420)$} & Spontaneous delivery & 351 & 83.6 \\
\hline & Instrumental delivery & 28 & 6.7 \\
\hline & $\mathrm{C} / \mathrm{S}$ delivery & 41 & 9.8 \\
\hline \multirow[t]{2}{*}{ PNC } & Yes & 273 & 65.0 \\
\hline & No & 147 & 35.0 \\
\hline \multirow[t]{3}{*}{ Number of PNC visit } & 1 & 64 & 23.4 \\
\hline & 2 & 131 & 48.0 \\
\hline & 3 & 78 & 28.6 \\
\hline \multirow[t]{3}{*}{ Birth order of index child } & 1 & 148 & 35.2 \\
\hline & $2-3$ & 198 & 47.2 \\
\hline & $\geq 4$ & 74 & 17.6 \\
\hline \multirow[t]{3}{*}{ Birth spacing } & No previous child & 148 & 35.2 \\
\hline & $<24$ months & 64 & 15.3 \\
\hline & $\geq 24$ months & 208 & 49.5 \\
\hline
\end{tabular}

\section{Maternal medical condition and breast problem}

Majority (89.3\%) of mothers did not face any of breast problems following the delivery of index child. From breast problem, mastitis (35.8\%) was the most common problem mothers faced followed by breast milk insufficiency $(31.1 \%)$. Majority $379(90.2 \%)$ of the mothers not faced any medical illness following the delivery of index child (Table 4). 
Table 4

Maternal medical condition and breast problem among mothers of children aged less than 12 months in Jinka town, South Ethiopia, 2018/19 ( $=420)$.

\begin{tabular}{|lllc|}
\hline Variable & Category & Frequency(n) & Percentage (\%) \\
\hline Any breast-feeding problem & Yes & 45 & 10.7 \\
\cline { 2 - 4 } & No & 375 & 89.3 \\
\hline Types of problem & Abscess & 8 & 17.8 \\
\cline { 2 - 4 } & Mastitis & 16 & 35.8 \\
\cline { 2 - 4 } & Cracked/sore nipples & 7 & 15.6 \\
\cline { 2 - 4 } Any maternal illness following delivery of index child & Bes & 14 & 31.1 \\
\cline { 2 - 4 } & Yest milk insufficiency & 41 & 9.8 \\
\cline { 2 - 4 }
\end{tabular}

Table 5

Breastfeeding knowledge of mothers of children aged less than 12 months in Jinka town, South Ethiopia, 2018/19 ( $\mathrm{n}=420$ )

\begin{tabular}{|c|c|c|c|}
\hline Knowledge questions & Response & Frequency(n) & $\begin{array}{l}\text { Percentage } \\
(\%)\end{array}$ \\
\hline \multirow[t]{2}{*}{ Breastfeeding is important for infant health } & Yes & 400 & 95.2 \\
\hline & No & 20 & 4.8 \\
\hline \multirow[t]{2}{*}{ Breastfeeding is important for maternal health } & Yes & 271 & 64.5 \\
\hline & No & 149 & 35.5 \\
\hline \multirow[t]{2}{*}{ An infant should be put to breast immediately after birth } & Yes & 346 & 82.4 \\
\hline & No & 74 & 17.6 \\
\hline \multirow[t]{2}{*}{ The first milk/colostrum should be given to an infant } & Yes & 361 & 86.0 \\
\hline & No & 59 & 14.0 \\
\hline \multirow[t]{2}{*}{ Pre-lacteal feeding is not needed for an infant before starting breast milk } & Yes & 290 & 69.0 \\
\hline & No & 130 & 31.0 \\
\hline \multirow{2}{*}{$\begin{array}{l}\text { Breast milk alone without water and other liquids is enough for an infant during the } \\
\text { first } 6 \text { months of life }\end{array}$} & Yes & 274 & 65.2 \\
\hline & No & 146 & 34.8 \\
\hline \multirow{2}{*}{$\begin{array}{l}\text { Starting from } 6 \text { month an infant should start complementary feeding and continued } \\
\text { breastfeeding up to } 2 \text { years and beyond }\end{array}$} & Yes & 289 & 68.8 \\
\hline & No & 131 & 31.2 \\
\hline
\end{tabular}


Table 6

Bivariable and multivariable logistic regression analysis of factors associated with colostrum avoidance practices among mothers of children aged less than 12 months in Jinka town, 2018/19.

\begin{tabular}{|c|c|c|c|c|c|c|}
\hline \multirow[t]{2}{*}{ Variable } & \multirow[t]{2}{*}{ Categories } & \multicolumn{2}{|c|}{$\begin{array}{l}\text { Colostrum avoidance } \\
\text { practice }\end{array}$} & \multirow[t]{2}{*}{$\begin{array}{l}\text { Crude OR with } \\
95 \% \mathrm{Cl}\end{array}$} & \multirow[t]{2}{*}{$\begin{array}{l}\text { Adjusted OR with } \\
95 \% \mathrm{Cl}\end{array}$} & \multirow[t]{2}{*}{$\begin{array}{l}\mathrm{P}- \\
\text { value }\end{array}$} \\
\hline & & Yes n (\%) & No n (\%) & & & \\
\hline \multirow{3}{*}{$\begin{array}{l}\text { Educational status of } \\
\text { Mother }\end{array}$} & $\begin{array}{l}\text { Unable to read and } \\
\text { write }\end{array}$ & $10(24.4)$ & $53(14)$ & $2.54(1.04-6.23)$ & $0.56(0.16-1.88)$ & 0.351 \\
\hline & Primary education & $19(46.3)$ & $164(43.3)$ & $1.56(0.73-3.32)$ & $1.02(0.42-2.45)$ & 0.96 \\
\hline & $\begin{array}{l}\text { Secondary and } \\
\text { above }\end{array}$ & $12(29.3)$ & $162(42.7)$ & 1 & 1 & \\
\hline \multirow[t]{2}{*}{ Prelacteal feeding } & Yes & $15(36.6)$ & $38(10.02)$ & $5.17(2.52-10.62)$ & $2.24(0.86-3.81)$ & 0.096 \\
\hline & No & $26(63.4)$ & $341(89.98)$ & 1 & 1 & \\
\hline \multirow[t]{2}{*}{ BF initiation } & Timely & $14(34.1)$ & $310(81.8)$ & 1 & 1 & \\
\hline & Delayed & $27(65.9)$ & $69(18.2)$ & $8.66(4.31-17.38)$ & $9.08(4.16-19.83)^{*}$ & 0.001 \\
\hline \multirow[t]{2}{*}{ BF counseling } & Yes & 16(39.02) & $252(66.49)$ & 1 & 1 & \\
\hline & No & $25(60.98)$ & 127(33.51) & $3.10(1.59-6.01)$ & $2.33(1.11-4.87) *$ & 0.024 \\
\hline \multirow[t]{2}{*}{ Place of delivery } & Health facility & $20(48.8)$ & $307(81)$ & 1 & 1 & \\
\hline & Home & $21(51.22)$ & 72(19) & $4.47(2.30-8.69)$ & $2.48(1.16-5.29) *$ & 0.018 \\
\hline \multirow[t]{2}{*}{ Post-natal care } & Yes & 19(46.3) & $254(67.02)$ & 1 & 1 & \\
\hline & No & $22(53.7)$ & 125(32.98) & $2.35(1.23-4.50)$ & $1.81(0.86-3.81)$ & 0.117 \\
\hline \multirow{2}{*}{$\begin{array}{l}\text { Knowledge on BF } \\
\text { practice }\end{array}$} & Good & $25(60.98)$ & $327(86.28)$ & 1 & 1 & \\
\hline & Poor & 16(39.020 & $52(13.72)$ & $4.02(2.01-8.04)$ & $4.55(1.95-10.63)^{*}$ & 0.001 \\
\hline \multicolumn{7}{|c|}{ Key: * =statistically significant at $p<0.05$ in multivariable logistic regression; } \\
\hline $1=$ indicated the ref $\epsilon$ & category. & & & & & \\
\hline
\end{tabular}

\section{Maternal knowledge on breast feeding}

From total respondents 290 (69\%) of mothers knows about as there is no need to give prelacteal feeding to the infant and 361 ( $86 \%$ ) of mothers knows about the importance the colostrum the infant. Three hundred fifty-two (83.8\%) mothers had good knowledge regarding to optimal breastfeeding practice while the remaining $68(16.2 \%)$ had poor knowledge concerning optimal breast -feeding practices (Table 5).

\section{The factors associated with colostrum avoidance practices}

In the final multivariable Logistic regression analysis, the time of initiation of breast feeding, BF counselling, place of delivery and knowledge on breast feeding practices were significant factors associated with colostrum avoidance practices. Mothers who delayed initiation of breast feeding were 9.08 times more likely to discard colostrum when compared to mothers who started breast feeding timely within one hour (AOR $=9.08,95 \% \mathrm{Cl} ; 4.16-19.83$ ). Mothers who didn't get breast feeding counselling were 2.33 times more likely to discard colostrum when compared to those mother who get breast feeding counselling ( $\mathrm{AOR}=2.33,95 \% \mathrm{Cl} ; 1.11-4.87$ ). Mothers who delivered the index child at home were 2.48 times more likely to discard colostrum when compared to mothers who gave birth at health facility $(\mathrm{AOR}=2.48,95 \% \mathrm{Cl} ; 1.16-5.29)$. Furthermore, colostrum avoidance practice were 4.55 times higher among mothers with poor knowledge on breast feeding practices when compared to their counterparts ( $\mathrm{AOR}=4.55,95 \% \mathrm{Cl} ; 1.95-10.63$ ) (Table 6). 


\section{Discussion}

This study was aimed to assess the prevalence of colostrum avoidance practices and associated factors among mothers of children aged less than 12 months in Jinka town, South Ethiopia. In this study the prevalence of colostrum avoidance practice was $9.8 \%$. This makes breastfeeding practices sub-optimal in Jinka town due to the introduction of pre-lacteal feeds and to the newborns and due to delayed initiation of first breast milk.

This result is consistent with the studies conducted in Axum town 6.3\% [27],North Wollo Zone 12\%[36], Raya Kobo District 13.5\% [26] and East Wollega Zone 8.8\% [43]. However, the finding of this study was higher than the studies done in Hula district, Sidama Region 3.9\% [44]. The difference between these studies might be due to the difference in community attitude towards colostrum feeding among ethnic groups. The other possible reason for this inconsistence of the finding might be sociodemographic difference among study participants.

The finding of this study is also lower than studies done in different developing countries. Utarkhand, India 92\% [20], Nepal 16.5\% [21], Pakistan 27.9\% [45], Burkina Faso 16\% [23],South Sudan 38.8\% [46] and Debre Tabor 25.6\% [25]. This difference could be due to the difference in maternal health service utilization between study populations. The other possible reasons could be due to the difference in year of the study. This could also be the place of residence and difference in maternal educational level. Hence, mothers who reside in the towns would have better access to maternal and child health services.

In this study, Mothers who delayed initiation of breast feeding were about nine times more likely to practice colostrum avoidance than those who initiated breast feeding within one hour. This result is consistent with the study done in Raya Kobo District, North Wollo zone, Pakistan, Nepal and Utarkhand, India respectively [20, 21, 26, 36, 45]. This could be because of the fact that those mothers who discarded the colostrum might take more time to discard it and initiate breastfeeding later. The reverse might be also correct. When mothers tend to initiate breastfeeding later, they would have more time for infant feeding malpractices like colostrum avoidance. This might be also due to the fact that when mother delay initiation of breast feeding infants suckling activity decreases and which in turn affects or decreases maternal milk secretion due to decreased breast stimulation, which finally made the mother to give other food to the infant and discard colostrum [28]. This might be due to knowledge gap about the importance of colostrum. The other possible reason might be due to mother's belief by considering colostrum as unclean and bad for the infant's health.

This study showed that mothers who didn't get breast feeding counseling were 2.3 times more likely to discard colostrum when compared to the mothers who get counseling regarding breast feeding. Other studies done in Hula District, Sidama Region and East Wollega Zone showed that breast feeding counseling during antenatal care improves timely initiation of first breast milk $[43,44]$. This might be due to that counseling is the tool to change the behaviors of mothers to reduce harmful nutritional malpractice during the time of pregnancy. This could be due to breast feeding counselling during perinatal period may increase mother's awareness on optimal breastfeeding practices that might decrease colostrum avoidance. But study done in Axum town revealed that there were no association between breast feeding counseling during ANC visit and colostrum avoidance practices [27]. This could be due to variation in utilization of maternal health services among study settings.

In this study, Mothers who delivered their index infants at home were 3.48 times more likely to engage in colostrum avoiding practices when compared with those who delivered in health facility. This finding was consistent with study conducted in Raya kobo district, North Wollo Zone, Pakistan and Utarkhand, India $[20,26,36]$. This indicates that strengthening maternal health service improves optimal breast feeding practices. This could be due to the fact that mothers, who gave birth at home, were more likely to be exposed to the traditional beliefs that favor colostrum discarding. In contrast, utilizing an institutional delivery would have an added benefit to receive immediate obstetric care, such as early initiation of breastfeeding which reduces the likelihood of practicing colostrum avoidance.

The odds of colostrum avoidance were 4.55 times higher among mothers with poor knowledge of optimal breast-feeding practices when compared to their counterparts. This finding was supported by other studies carried out in Axum Town, Raya Kobo District, Hula District and Utarkhand, India [20,26, 27, 44]. These supporting evidences revealed that improving the mother's awareness of optimal infant feeding practices reduces the likelihood of colostrum avoidance. This might be due to awareness of mothers about breast feeding practices and the nutritional value of colostrum decreases the likelihood of colostrum discarding. 
The limitation of this study were that the information obtained from mothers having children aged less than 12 months is subject to recall bias and also It is difficult to establish temporal relationship as the study design was cross-sectional.

\section{Conclusion And Recommendation}

Colostrum avoidance practice among mothers of children aged less than 12 months in Jinka town was found to be high when compared to WHO recommendation. Delayed initiation of breast feeding, lack of breast-feeding counselling, home delivery of index child and poor knowledge on breastfeeding feeding practice were significant factors associated with colostrum avoidance practices of mothers. Based on the finding the following recommendations' are forwarded; Awareness creation activities on the nutritional value of colostrum, promotion of institutional delivery and improving breastfeeding counseling are important interventions to reduce colostrum avoidance practices in Jinka Town.

\section{Abbreviations}

ANC: Antenatal Care; AOR: Adjusted Odds Ratio; Cl: Confidence Interval; COR: Crude Odds Ratio; CSA: Central Statistical Agency; EBF: Exclusive Breast Feeding; EDHS: Ethiopian Demographic and Health Survey; IYCF: Infant and Young Feeding Practice; PLF: Prelacteal Feeding; SPSS: Statistical Package for Social Sciences; UNICEF: United Nations children's emergency fund; WHO: World Health Organization.

\section{Declarations}

\section{Ethics approval and consent to participate:}

The study protocol was approved by the Institutional Review Board (IRB) of College of Medicine and Health Science, Arba Minch University. Based on the approval, an official letter of support was written by Arba Minch University Public Health Department to Jinka Town health office. At last data was collected after assuring the confidentiality of responses and obtaining informed consent from the study participant.

\section{Participant consent:}

Obtained

\section{Consent for publication:}

Not applicable.

\section{Availability of data and material:}

For those who are interested; the datasets of this study could be accessed from the corresponding author on reasonable request.

\section{Competing interests:}

The authors declare that they have no competing interests.

\section{Funding:}

Not applicable

\section{Authors' contributions}


EA conceived and designed the study, supervised the data collection, performed the analysis, interpretation of data and drafted the manuscript. FG assisted in designing the study, data interpretation and critically reviewed the manuscript. MB assisted in data interpretation and reviewed the manuscript critically. All authors read and approved the final manuscript.

\section{Acknowledgment:}

we would like to express our heartfelt appreciation to the Jinka Town health office, data collectors, supervisors and study subjects.

\section{References}

1. WHO U. Global Strategy for Infant and Young Child Feeding. 2003 [Available from: http://apps.who.int/iris/bitstream/handle/10665/42590/9241562218.pdf;jsessionid=FB748ED1F90AFF4AB552F026E7D0D607? sequence $=1$.

2. Goldman AS. Modulation of the gastrointestinal tract of infants by human milk. Interfaces and interactions. An evolutionary perspective. J Nutr. 2000;130(2):426S-31S.

3. Horta BL, Loret de Mola C, Victora CG. Long-term consequences of breastfeeding on cholesterol, obesity, systolic blood pressure and type 2 diabetes: a systematic review and meta-analysis. Acta paediatrica. 2015;104:30-7.

4. Jedrychowski W, Perera F, Jankowski J, Butscher M, Mroz E, Flak E, et al. Effect of exclusive breastfeeding on the development of children's cognitive function in the Krakow prospective birth cohort study. Eur J Pediatrics. 2012;171(1):151-8.

5. Himani BK, Kumar P. Effect of initiation of breastfeeding within one hour of the delivery on" maternal-infant bonding. Nursing and Midwifery Research Journal. 2011;7(3).

6. Begum K, Dewey KG. Impact of early initiation of exclusive breastfeeding on newborn deaths. 2010.

7. Khanal V, Adhikari M, Sauer K, Zhao Y. Factors associated with the introduction of prelacteal feeds in Nepal: findings from the Nepal demographic and health survey 2011. International Breastfeeding Journal. 2013;8(1):9.

8. Nguyen PH, Keithly SC, Nguyen NT, Nguyen TT, Tran LM, Hajeebhoy N. Prelacteal feeding practices in Vietnam: challenges and associated factors. BMC Public Health. 2013;13(1):932.

9. Legesse M, Demena M, Mesfin F, Haile D. Prelacteal feeding practices and associated factors among mothers of children aged less than 24 months in Raya Kobo district, North Eastern Ethiopia: a cross-sectional study. International Breastfeeding Journal. 2014;9(1):189.

10. WHO/UNICEF. Baby-friendly hospital initiative (BFHI).Revised, Updated and Expanded for Integrated Care.Section 3, Breastfeeding Promotion and Support in a Babyfriendly Hospital: A 20-hour Course for Maternity Staff. 2009.

11. Haider RRS, Sanghvi T, et al. Breastfeeding in infancy: identifying the program-relevant issues in Bangladesh. Int Breastfeed J 2010;5:21. 2010.

12. Rogers NAJ, Moore D, et al. Colostrum avoidance, prelacteal feeding and late breast-feeding initiation in rural Northern Ethiopia.Public Health Nutr 2011;14: 2029-36. 2011.

13. Tamiru DBT, Loha E, et al. Sub-optimal breastfeeding of infants during the first six months and associated factors in rural communities of Jimma Arjo Woreda, Southwest Ethiopia.. BMC Public Health 2012;12:363. 2012.

14. Sriram S, Soni P, Thanvi R, Prajapati N, Mehariya K. Knowledge, attitude and practices of mothers regarding infant feeding practices. National Journal of Medical Research. 2013;3(2):147-50.

15. LLLI. What is colostrum? How does it benefit my baby? 2016.. 2016.

16. Bayissa ZB, Geletaw BKG,A, et al. Knowledge and practice of mothers towards exclusive breastfeeding and its associated factors in Ambo woreda West Shewa zone Oromia region Ethiopia. Epidemiology. 2015;5(1):1-7.

17. Adhikari M, Karkee VK,R, Gavidia T,. "Factors associated with early initiation of breastfeeding among Nepalese mothers: further analysis of Nepal Demographic and Health Survey, 2011,". International Breastfeeding Journal, vol 9, no 1, p 21, 2014. 2014.

18. Agrawal D KA, and Khare BB,. "Study on the current status of infant and childhood feeding practice.Indian Pediatrics,. " Indian Pediatrics, 2013. 2013.

19. Gunnlaugsson G, Einarsdottir J. “Colostrum and ideas about bad milk: A case study from Guinea-Bissau,” Social Science \& Medicine,. 2013; vol. 36, no. 3, pp. 283-288, 2013. 
20. Koel, Mukherjee e, al. Colostrum Avoidance and Breastfeeding Practices among Mothers of Khos Tribal Community of Uttarakhand:. Journal of the Anthropological Survey of India, 67(1): (45-55), 2018. 2018.

21. Shiva, Bhandari et a. Determinants of infant breastfeeding practices in Nepal: a national study. Bhandari et al International Breastfeeding Journal (2019) 14:14 2019.

22. Sohail JKA. Knowledge, attitude and practice of mothers regarding colostrum feeding to newborns in rural Pakistan: a crosssectional study.. Khyber Med Univ J 2017;9(4):192-196. 2017.

23. Munos MK, Mullany LC, Maïga A, Baya B, Bryce J. Coverage and determinants of newborn feeding practices in rural Burkina Faso. J Perinatol. 2014;34(5):369.

24. Yohannes Haile

10.11648/j.ejcbs.20160206.15

Misgan Legesse Liben TA. Yohannes Haile.. The Role of Colostrum Feeding on the Nutritional Status of Preschool Children in Afambo District, Northeast Ethiopia: Descriptive Cross Sectional Study.. European Journal of Clinical and Biomedical Sciences 2016;Vol. 2, No. 6, 2016, pp. 87-91. doi: 10.11648/j.ejcbs.20160206.15.

25. Goshu Aa. Early initiation of breastfeeding and colostrum feeding among mothers of children aged less than 24 months in Debre Tabor, northwest Ethiopia. BMC Res Notes. (2019) 12:65. 2019.

26. Legesse M, Demena M, Mesfin F, Haile D. Factors associated with colostrum avoidance among mothers of children aged less than 24 months in Raya Kobo district, North-eastern Ethiopia: community-based cross-sectional study. J Trop Pediatr. 2015;61(5):357-63.

27. Woldesenbet Colostrum avoidance and associated factors among mothers having children less than 2 years of age in Aksum town, Tigray, Ethiopia. 2018;BMC Res Notes (2018) 11:601.

28. Tewabe T. Prelacteal Feeding Practices among Mothers in Motta Town, Northwest Ethiopia: A Cross-sectional Study. Ethiopian Journal of Health Sciences. 2018;28(4).

29. Singh B. Knowledge, attitude and practice of breastfeeding-A case study. Eur J Sci Res. 2010;40(3):404-22.

30. WHO. Global health risks: mortality and burden of disease attributable to selected major risks. Geneva2009 [.

31. Ali S, Ali SF, Imam AM, Ayub S, Billoo AG. Perception and practices of breastfeeding of infants 0-6 months in an urban and a semi-urban community in Pakistan: a cross-sectional study. J Pak Med Assoc. 2011;61(1):99.

32. Onah S, Osuorah DIC, Ebenebe J, Ezechukwu C, Ekwochi U, Ndukwu I. Infant feeding practices and maternal socio-demographic factors that influence practice of exclusive breastfeeding among mothers in Nnewi South-East Nigeria: a cross-sectional and analytical study. International breastfeeding journal. 2014;9(1):6.

33. misgan Legesse Liben TA, Yohannes Haile. Determinants of Child Malnutrition among Agro Pastorals in Afambo district NortheasternEthiopia. Health science journal. 2016;10 No:4:15.

34. Teshome B, Kogi-Makau W, Getahun Z, Taye G. Magnitude and determinants of stunting in children underfive years of age in food surplus region of Ethiopia: the case of west gojam zone. Ethiopian Journal of Health Development. 2009;23(2).

35. Khanal V, Lee AH, Karkee R, Binns CW. Prevalence and factors associated with prelacteal feeding in Western Nepal. Women Birth. 2016;29(1):12-7.

36. Liben Ya. Effects of home delivery on colostrum avoidance practices in North Wollo zone, an urban setting, Ethiopia: a cross sectional study. Journal of Health Population Nutrition. 2018;37:4.

37. Federal Ministry of Health FHD. National strategy for infant and young child feeding Ethiopia2004 [Available from: https://motherchildnutrition.org/nutrition-protection-promotion/pdf/mcn-national-strategy-for-infant-and-young-child-feedingethiopia.pdf.

38. Fetene $\mathrm{N}$, Linnander E, Fekadu B, Alemu H, Omer H, Canavan M, et al. The Ethiopian health extension program and variation in health systems performance: what matters? PloS one. 2016;11(5):e0156438.

39. Kim SS, Rawat R, Mwangi EM, Tesfaye R, Abebe Y, Baker J, et al. Exposure to large-scale social and behavior change communication interventions is associated with improvements in infant and young child feeding practices in Ethiopia. PloS one. 2016;11(10):e0164800.

40. Central Statistical Agency and ICF Macro. Ethiopia Demographic and Health Survey 2016 Maryland,USA 2016 [. 
41. WHO U. Capture the moment: Erly initiation of breast feeding,the best start of every new bornNewyork2018[Availablefrom:https://www.unicef.org/publications/files/UNICEF_WHO_Capture_the_moment_EIBF_2018.pdf.

42. JTh. Town health office plan,2018 2018 [.

43. Hailemariam TW, Adeba E, Sufa A. Predictors of early breastfeeding initiation among mothers of children under 24 months of age in rural part of West Ethiopia. BMC Public Health. 2015;15(1):1076.

44. Shibru Hoche BM, Negash Wakgari. SubOptimal Breast Feeding and Its Associated Factors in Rural Communities of Hula District, Southern Ethiopia: A Cross-Sectional Study. Ethiop J Health Sci. 2017;28(1):49.

45. Sohail J, Khaliq A. Knowledge. Attitude And Practice Of Mothers Regarding Colostrum Feeding To Newborns In Rural Pakistan: A Cross-Sectional Study. Khyber Medical University Journal. 2017;9(4).

46. Tongun JB, Sebit MB, Ndeezi G, Mukunya D, Tylleskar T, Tumwine JK. Prevalence and determinants of pre-lacteal feeding in South Sudan: a community-based survey. Global health action. 2018;11(1):1523304. 